\title{
STRUCTURE AND SERVICE PROPERTIES OF HYBRID LASER-ARC WELDED JOINTS OF 14KhGN2MDAFB STEEL
}

\author{
L.I. MARKASHOVA, V.D. POZNYAKOV, E.N. BERDNIKOVA, S.L. ZHDANOV, \\ V.D. SHELYAGIN and T.A. ALEKSEENKO \\ E.O. Paton Electric Welding Institute, NASU \\ 11 Kazimir Malevich Str., 03680, Kiev, Ukraine. E-mail: office@paton.kiev.ua
}

\begin{abstract}
The paper represents the results of experimental investigations of peculiarities in formation of structure and phase composition of welded joints from high-strength $14 \mathrm{KhGN} 2 \mathrm{MDABF}$ steel at different speeds $\left(v_{\mathrm{w}}=72,90\right.$ and $\left.110 \mathrm{~m} / \mathrm{h}\right)$ of hybrid laser-arc welding. Information received at different structural levels (from grain to dislocation) is used for analytical evaluation of effect of the structural parameters on mechanical properties and fracture toughness of the welded joints depending on modes of laser-arc welding. The investigations of effect of the structural factors on mode of crack formation under conditions of different dynamic strength tests at external bend loading as well as cyclic loading were carried out for evaluation of a complex of welded joint service characteristics. A role of the structural factors in change of level of local internal stresses, i.e. sources of nucleation and propagation of cracks in the welded joint metal, is shown. The optimum technological modes of hybrid laser-arc welding are determined. They provide for the high indices of mechanical properties and crack resistance of metal under service conditions of external loading from point of view of structure and phase composition. 17 Ref., 2 Tables, 10 Figures.
\end{abstract}

Keywords : high-strength steel, hybrid laser-arc welding, welded joints, structure, phase composition, mechanical properties, fracture toughness, external loading, crack resistance

As a rule, high-strength steels with yield limit more than $700 \mathrm{MPa}$ are currently applied for critical machines and mechanisms having difficult for operation conditions. They in combination with the most optimum technological parameters of welding of such materials should provide for a necessary complex of service characteristics of the welded joints, first of all, their strength, ductility and crack resistance [1,2]. The range of welding speeds in use of the classical technologies of mechanized metal arc welding for such steels makes $v_{\mathrm{w}}=18-50 \mathrm{~m} / \mathrm{h}$ at $w_{6 / 5} \approx 10-38^{\circ} \mathrm{C} / \mathrm{s}$ rate of cooling.

However, today advanced laser technologies find more and more application. Among them is a hybrid laser-arc (HLA) welding [3-5] which allows producing quality welded joints using higher welding speeds up to $110 \mathrm{~m} / \mathrm{h}$ and $w_{6 / 5} \approx 30-100^{\circ} \mathrm{C} / \mathrm{s}$. It significantly increases efficiency of the process (several times in comparison with arc welding) as well as provides for $8-15 \%$ rise of strength indices and 1.5-2 times ductility of the welded joints. At that, a significant change of welding zone geometry shall be noted, i.e. 3-5 times reduction of width of weld and HAZ. Taking into account a significant change of process modes and, respectively, the welding zone geometry, noticeable changes are to be expected in the structures formed in the new type welded joints, which, as is well known, in many respects determine their properties [6-9].

In order to optimize the welding parameters, the most of process experiments in hybrid welding are dedicated to investigation of interaction between arc and laser, arc stabilizing and its spatial attachment by laser radiation, effect of shielding gas, arc voltage, welding speed and current on penetration depth [9-13]. Currently, the main task of technologists and researchers [14-17] is investigation of the peculiarities of laser and hybrid processes, their effect on weld formation, possible advantages and elimination of disadvantages of laser and arc constituents as well as effect of process parameters on structure formation in the welding zone.

The aim of present work is a detailed investigation of the peculiarities of phase and structural changes at all structural levels (from grain to dislocation) in the metal of joints produced using HL Awelding depending on parameters of technological process. Besides, a relevant task is the evaluation of role of specific structure-phase constituents, forming at different welding modes in optimizing the mechanical characteristics of welded joints, which are valuable for service conditions, namely indices of strength ductility and crack resistance. 
Materials and investigation procedures. The work was carried out on samples of high-strength steel $14 \mathrm{KhGN} 2 \mathrm{MDAFB}$ (\%: $0.183 \mathrm{C} ; 1.19 \mathrm{Cr} ; 0.98 \mathrm{Mn}$; $2.07 \mathrm{Ni} ; 0.22 \mathrm{Mo} ; 0.08 \mathrm{~V} ; 0.33 \mathrm{Si}$; not more than $0.018 \mathrm{P}$ and $0.005 \mathrm{~S}$ ) of up to $10 \mathrm{~mm}$ thickness using welding wire $\mathrm{Sv}-10 \mathrm{KhN} 2 \mathrm{GSMFTYu}(\%: \leq 0.1 \mathrm{C} ; 0.7 \mathrm{Cr}$; $0.4 \mathrm{Mn} ; 0.22 \mathrm{Mo} ; 0.15 \mathrm{~V} ; 0.24 \mathrm{Si}$; not more than $0.007 \mathrm{~S}$ ) at the three following modes of HLA welding:

- $1^{\mathrm{st}}-v_{\mathrm{w}}=72 \mathrm{~m} / \mathrm{h}, I \sim 125 \mathrm{~A}, U_{\mathrm{a}} \sim 23 \mathrm{~V}$;

- $2^{\text {nd }}-v_{\mathrm{w}}=90 \mathrm{~m} / \mathrm{h}, I \sim 150 \mathrm{~A}, U_{\mathrm{a}}^{\mathrm{a}} \sim 25 \mathrm{~V}$;

- $3^{\text {rd }}-v_{\mathrm{w}}=110 \mathrm{~m} / \mathrm{h}, I \sim 200 \mathrm{~A}, U_{\mathrm{a}} \sim 26 \mathrm{~V}$.

Indicated modes provide for HAZ metal cooling in the temperature interval $600-500{ }^{\circ} \mathrm{C}$ at $w_{6 / 5}=$ $=58-62{ }^{\circ} \mathrm{C} / \mathrm{s}$ rate. $\mathrm{Nd}$ :YAG laser DY 044 (Rofin Synar, Germany) to $4.4 \mathrm{~kW}$ power was used as laser radiation source and mixture $\mathrm{Ar}+\mathrm{CO}_{2}$ with 15-20 1/min consumption - as a shielding gas.

The structure-phase characteristics, i.e. size of grain and subgrain structure, distribution of phase precipitates, peculiarities of zones of brittle and ductile fracture, distribution of dislocation density in the weld metal and different areas of welded joint HAZ, were examined at all structural levels using complex of experimental methods of current physical materials science, including optical metallography (microscopes «Versamet-2» and «Neophot-32»), PHILIPS analytical scanning SEM-515 and JEOL transmission electron microscope JEM-200CX. Hardness of the examined metal was measured at LECO hardness gage M-400 at $0.1 \mathrm{~kg}$ loading.

The complex investigations provided for the evaluation of differential contribution of the separate structure-phase constituents and structural parameters in change of the integral values of strength $\sum \sigma_{y}$ and ductile fracture $K_{1 c}$ as well as local internal stresses $\tau_{\text {l.in }}$ (zones of nucleation and propagation of cracks) in different areas of the welded joints at applied modes of hybrid welding.
The results of mechanical tests (Table 1) determine that the highest indices of yield limit $\sigma_{0.2}$ and tensile strength $\sigma_{t}$ are typical for welds made at $v_{w}=90 \mathrm{~m} / \mathrm{h}$.

However, in this case, the ductility index $\psi$ is significantly reduced (1.6 times) in comparison with that at $v_{\mathrm{w}}=72$ and $110 \mathrm{~m} / \mathrm{h}$. The impact bending tests at temperature from +20 to $-40{ }^{\circ} \mathrm{C}$ showed some increase of impact toughness in the weld metal of up to $K C V_{+20}=75.7\left(\right.$ at $\nu_{\mathrm{w}}=72 \mathrm{~m} / \mathrm{h}$ ) and $K C V_{-40}=52.1 \mathrm{~J} / \mathrm{cm}^{2}$ (at $v_{\mathrm{w}}=90 \mathrm{~m} / \mathrm{h}$ ). However, in the last case, $K C V_{-40}$ is significantly reduced (1.4 times) (in comparison with $v_{\mathrm{w}}=72$ and $110 \mathrm{~m} / \mathrm{h}$ ) for HAZ metal.

Experiment results. The investigations were carried out for studying the changes of different phase constituents (upper and lower bainite $\mathrm{B}_{\mathrm{U}}$ and $\mathrm{B}_{\mathrm{L}}$, martensite $\mathrm{M}$, their volume fraction $v$, microhardness $H V$, as well as different structural parameters (dimension of grain, sub-grain structure $-D_{\mathrm{g}}, d_{\mathrm{s}}$ ), nature of dislocation density and distribution, and peculiarities of the fracture zone of welded joints (ductile, brittle etc.) depending on $v_{w}=72,90$ and $110 \mathrm{~m} / \mathrm{h}$. The experiments were performed for all the most significant zones of the welded joints, i.e. weld metal and HAZ.

Thus, the following is typical for the different zones of welded joint with a structure of base metal, consisting of bainite ferrite (B-F) grains with $D_{\mathrm{g}}=15-25 \mu \mathrm{m}$ and microhardness HV 2700$2850 \mathrm{MPa}$ at $v_{\mathrm{w}}=72 \mathrm{~m} / \mathrm{h}$. The structure of weld metal (Sv-10KhN2GSMFTYu) and HAZ (Figure 1, a) is $\mathrm{B}-\mathrm{M}$ with prevailing $(V \sim 60-80 \%)$ formation of structures of $\mathrm{B}_{\mathrm{L}}$ with $D_{\mathrm{g}}=(30-120) \times(170-350) \mu \mathrm{m}$ in the weld metal at $H V=3660-4010 \mathrm{MPa}$ (Figures 2, $a$ and 3,a). Microhardness in an overheating area (HAZ I) at transfer from HAZ makes $H V \sim 3830-3900 \mathrm{MPa}$, and grain size for this zone reduces to $D_{\mathrm{g}} \sim 30-60 \mu \mathrm{m}$ (Figure $2, d$ and 3,a). In area of HAZ recrystallization the structure becomes more refined (2-4 times) at decrease of microhardness to $H V=3510-3660 \mathrm{MPa}$.

Table 1. Mechanical properties of HLA-welded joints of 14KhGN2MDAFB steel investigated

\begin{tabular}{|c|c|c|c|c|c|c|c|}
\hline \multirow{3}{*}{$v_{\mathrm{w}}, \mathrm{m} / \mathrm{h}$} & \multirow[b]{2}{*}{$\sigma_{0.2}$} & \multirow[b]{2}{*}{$\sigma_{\mathrm{t}}$} & \multirow{2}{*}{$\delta_{5}$} & \multirow[b]{2}{*}{$\psi$} & \multicolumn{3}{|c|}{$K C V, \mathrm{~J} / \mathrm{cm}^{2}$, at $T,{ }^{\circ} \mathrm{C}$} \\
\hline & & & & & \multicolumn{2}{|c|}{ Weld } & HAZ \\
\hline & \multicolumn{2}{|c|}{$\mathrm{MPa}$} & \multicolumn{2}{|c|}{$\%$} & +20 & -40 & -40 \\
\hline \multirow[t]{4}{*}{72} & 851.8 & 1068.3 & 12.7 & 59.6 & 61.4 & 35.7 & 93.5 \\
\hline & 963.6 & $\underline{1189.8}$ & 9.3 & $\underline{63.7}$ & $\underline{90.0}$ & $\underline{40.9}$ & 79.9 \\
\hline & 907.7 & 1129.0 & 11.0 & 61.6 & 75.7 & 38.3 & $\underline{80.9}$ \\
\hline & & & & & & & 84.7 \\
\hline \multirow[t]{4}{*}{90} & 1138.1 & 1326.6 & 10.0 & 40.8 & 64.5 & 59.1 & 50.4 \\
\hline & $\underline{1156.3}$ & $\underline{1319.7}$ & & $\underline{35.6}$ & $\underline{58.6}$ & $\underline{45.2}$ & 61.7 \\
\hline & 1147.2 & 1323.1 & & 38.2 & 61.5 & 52.1 & $\underline{65.7}$ \\
\hline & & & & & & & 59.2 \\
\hline \multirow[t]{4}{*}{110} & 991.5 & 1078.1 & 9.7 & 59.6 & 58.7 & 41.9 & 90.1 \\
\hline & $\underline{982.1}$ & $\underline{1088.9}$ & $\underline{14.0}$ & & $\underline{81.2}$ & 29.7 & 66.5 \\
\hline & 986.8 & 1083.5 & 11.8 & & 70.0 & 35.8 & $\underline{96.7}$ \\
\hline & & & & & & & 84.4 \\
\hline
\end{tabular}



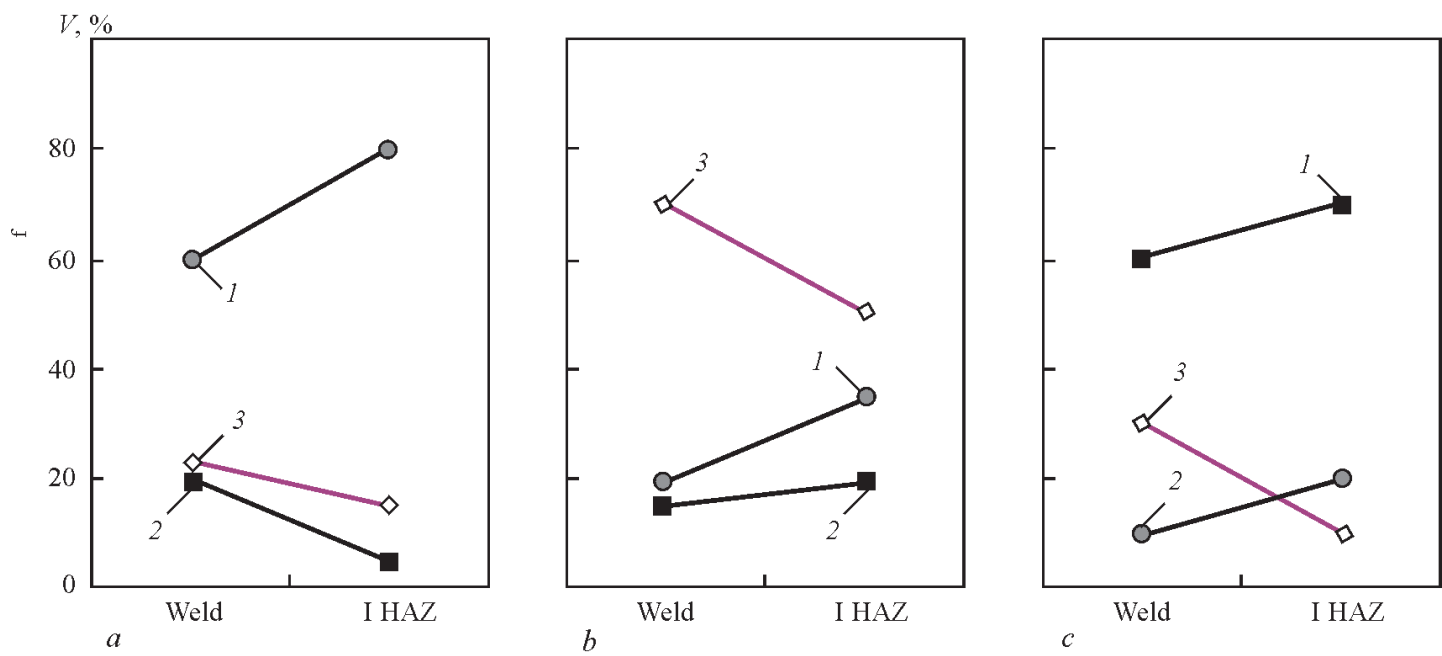

Figure 1. Change of volume fraction of structural constituents in weld metal and zone I of HAZ of HLA-welded joints at $v_{\mathrm{w}}=72(a)$, $90(b), 110(c) \mathrm{m} / \mathrm{h}: 1-\mathrm{B}_{\mathrm{L}} ; 2-\mathrm{B}_{\mathrm{U}} ; 3-\mathrm{M}$

Formation of ferrite-bainite structure at $H V=3360$ $3510 \mathrm{MPa}$ and $D_{\mathrm{g}}=5-15 \mu \mathrm{m}$ is typical at transfer to the base metal in area of incomplete recrystallization.

Thus, mainly $B_{L}$ structure is formed at $v_{w}=72 \mathrm{~m} / \mathrm{h}$ in the weld metal and HAZ, and at transfer from weld to HAZ the grain structure is $2-4$ times refined at $12 \%$ uniform reduction of microhardness.

Formation of mainly $(V \sim 50-70 \%)$ (Figure $1, b)$ martensite structure (tempered martensite) with $D_{\mathrm{g}} \sim$ $\sim(30-80) \times(150-300) \mu \mathrm{m}$ at $H V=4050-4422 \mathrm{MPa}$ (Figures 2, $b$ and $3, b$ ) is typical for the weld metal at $v_{\mathrm{w}}=90 \mathrm{~m} / \mathrm{h}$. The size of grain is somewhat reduced (to $D_{\mathrm{g}} \sim 25-50 \mu \mathrm{m}$ ) at transfer to the overheating area in HAZ with insignificant reduction of microhardness to $H V=3830-4050 \mathrm{MPa}$ (Figures 2, $e$ and 3, $b$ ). The HAZ structure is much more refined (2 times to $\left.D_{\mathrm{g}}=10-20 \mu \mathrm{m}\right)$ with reduction of microhardness to
$H V \sim 3660-3830 \mathrm{MPa}$ as transfer to the base metal in area of recrystallization. Formation of $\mathrm{F}-\mathrm{B}$ structure $\left(D_{\mathrm{g}}=10-20 \mu \mathrm{m}\right)$ at $H V=3220-3700 \mathrm{MPa}$ is typical for the following area of incomplete recrystallization.

Increase of welding speed from 72 to $90 \mathrm{~m} / \mathrm{h}$ results in a change of the phase composition of weld metal and HAZ from B-M to $M$ type as well as relationship of the structural constituents in HAZ metal, i.e. 2-3 times reduction of $B_{L}$ volume faction at increase ( 3 times) of $\mathrm{M}_{\text {temp }}$ fraction, that as a consequence provides for the maximum indices of strength, however, give rise to significant 1.6 times reduction (see Table 1) of ductility in the weld.

At the maximum $v_{\mathrm{w}}=110 \mathrm{~m} / \mathrm{h}$ the phase composition of weld metal and HAZ is represented by B-M structure with prevailing $(V \sim 60-70 \%)$ (Figure $1, c)$ formation of the $\mathrm{B}_{\mathrm{U}}$ structures with $D_{\mathrm{g}}=(20$
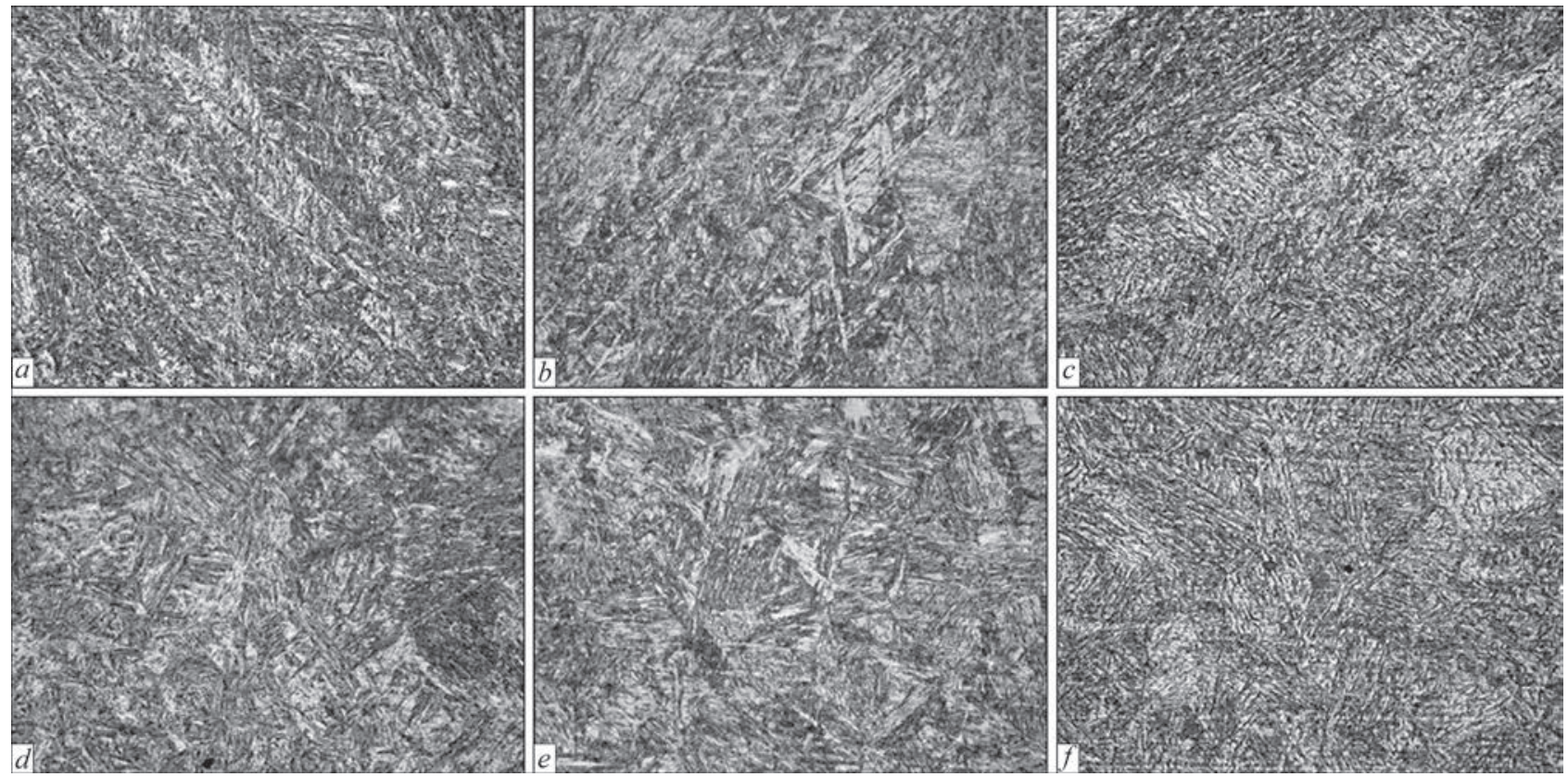

Figure 2. Microstructure $(\times 500)$ of weld metal $(a-c)$ and HAZ overheating area $(d-f)$ at $v_{\mathrm{w}}=72(a, d), 90(b, e)$ and $110(c, f) \mathrm{m} / \mathrm{h}$ 

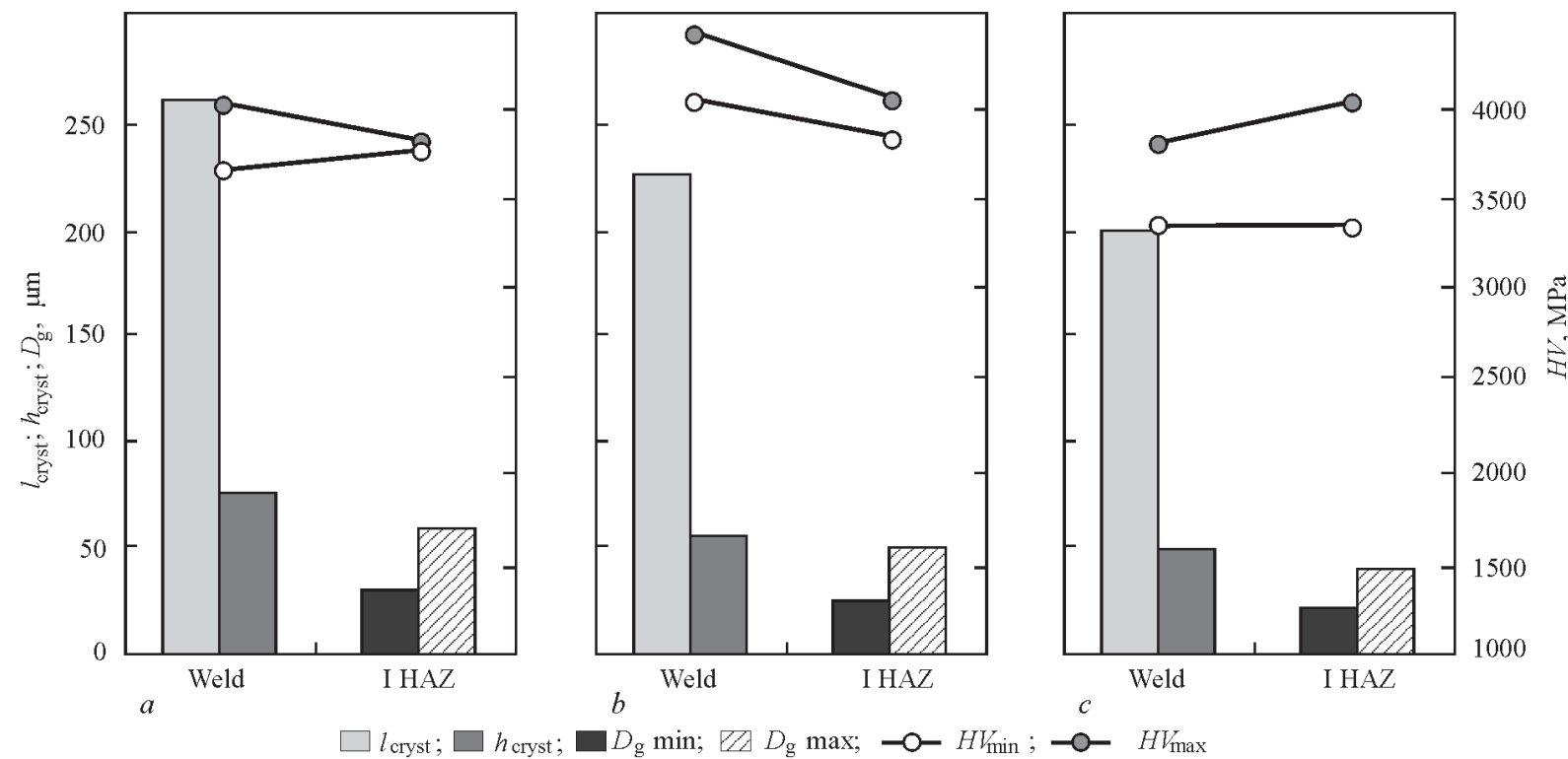

b

Figure 3. Change of average size of crystallites $h_{\text {cryst }}$ and $l_{\text {cryst }}$, grain size $D_{\mathrm{g}}$, microhardness $H V$ in weld metal and HAZ at $v_{\mathrm{w}}=72(a)$, $90(b)$ and $110(c) \mathrm{m} / \mathrm{h}$

$80) \times(150-250) \mu \mathrm{m}$ and microhardness $H V \sim 3360$ $4010 \mathrm{MPa}$ (Figures 2,c and 3,c). However, the grain size is 2 times reduced to $D_{\mathrm{g}}=20-40 \mu \mathrm{m}$ (Figures 2, $f$ and $3, c$ ) at transfer to HAZ in the area of overheating, and the metal of incomplete recrystallization area is characterized by formation of $\mathrm{F}-\mathrm{B}$ structure with $H V=3360-3510 \mathrm{MPa}$ and $D_{\mathrm{g}}=5-20 \mu \mathrm{m}$.
Thus, increase of welding speed to $110 \mathrm{~m} / \mathrm{h}$ (regardless the fact that the phase composition of weld metal and HAZ overheating area are similar as at $v_{w}=$ $=72 \mathrm{~m} / \mathrm{h}$, i.e. $\mathrm{B}-\mathrm{M})$ promotes for significant reduction of volume fraction of $B_{L}$ to $10-20 \%$ and prevailing formation of $\mathrm{B}_{U}$ structure $(v=60-70 \%)$. Such structural changes can result in non-uniform level of

Table 2. Change of volume fraction of fracture mode, size of facets of brittle intragranular chip, pits of ductile fracture for fracture zones in welded joint metal at different speeds of HLA welding

\begin{tabular}{|c|c|c|c|c|c|c|c|}
\hline \multirow{3}{*}{ Fracture mode } & \multicolumn{7}{|c|}{$v_{\mathrm{w}} \sim 72 \mathrm{~m} / \mathrm{h}$} \\
\hline & \multirow{2}{*}{$\frac{T_{\text {test }},{ }^{\circ} \mathrm{C}}{\text { Zone }}$} & \multicolumn{2}{|c|}{+20} & \multicolumn{2}{|c|}{-40} & \multicolumn{2}{|c|}{-40} \\
\hline & & I Weld & II Weld & I Weld & II Weld & I HAZ & II HAZ \\
\hline \multirow{2}{*}{ Brittle intragranular } & $V, \%$ & - & - & $50-60$ & $80-90$ & - & 5 \\
\hline & $d_{\mathrm{fac}}, \mu \mathrm{m}$ & - & - & $10-50$ & $7-50$ & - & $7-10$ \\
\hline \multirow{2}{*}{ Ductile } & $V, \%$ & 100 & 100 & $40-50$ & $10-20$ & 100 & 95 \\
\hline & $d_{\text {pit }}, \mu \mathrm{m}$ & $1-3$ & $1-5$ & $1-3$ & $1-3$ & $1-5$ & $1-10$ \\
\hline & \multicolumn{7}{|c|}{$v_{\mathrm{w}} \sim 90 \mathrm{~m} / \mathrm{h}$} \\
\hline \multirow{2}{*}{ Brittle intragranular } & $V, \%$ & $1-2$ & - & $40-50$ & $70-80$ & - & 20 \\
\hline & $d_{\mathrm{fac}}, \mu \mathrm{m}$ & $5-7$ & - & $20-50$ & $10-50$ & - & $7-14$ \\
\hline \multirow{2}{*}{ Ductile } & $V, \%$ & 98 & 100 & $50-60$ & $20-30$ & 100 & 80 \\
\hline & $d_{\mathrm{pit}}, \mu \mathrm{m}$ & $1-3$ & $1-3$ & $1-3$ & $1-3$ & $1-6$ & $1-50$ \\
\hline & \multicolumn{7}{|c|}{$v_{\mathrm{w}} \sim 110 \mathrm{~m} / \mathrm{h}$} \\
\hline \multirow{2}{*}{ Brittle intragranular } & $V, \%$ & $20-30$ & 10 & $70-80$ & 95 & - & 35 \\
\hline & $d_{\mathrm{fac}}, \mu \mathrm{m}$ & $15-50$ & $30-50$ & $20-60$ & $20-60$ & - & $10-20$ \\
\hline \multirow{2}{*}{ Ductile } & $V, \%$ & $70-80$ & 90 & $30-40$ & $0-5$ & 100 & 65 \\
\hline & $d_{\mathrm{pit}}, \mu \mathrm{m}$ & $1-4$ & $1-4$ & $1-3$ & $1-3$ & $1-10$ & $1-7$ \\
\hline
\end{tabular}



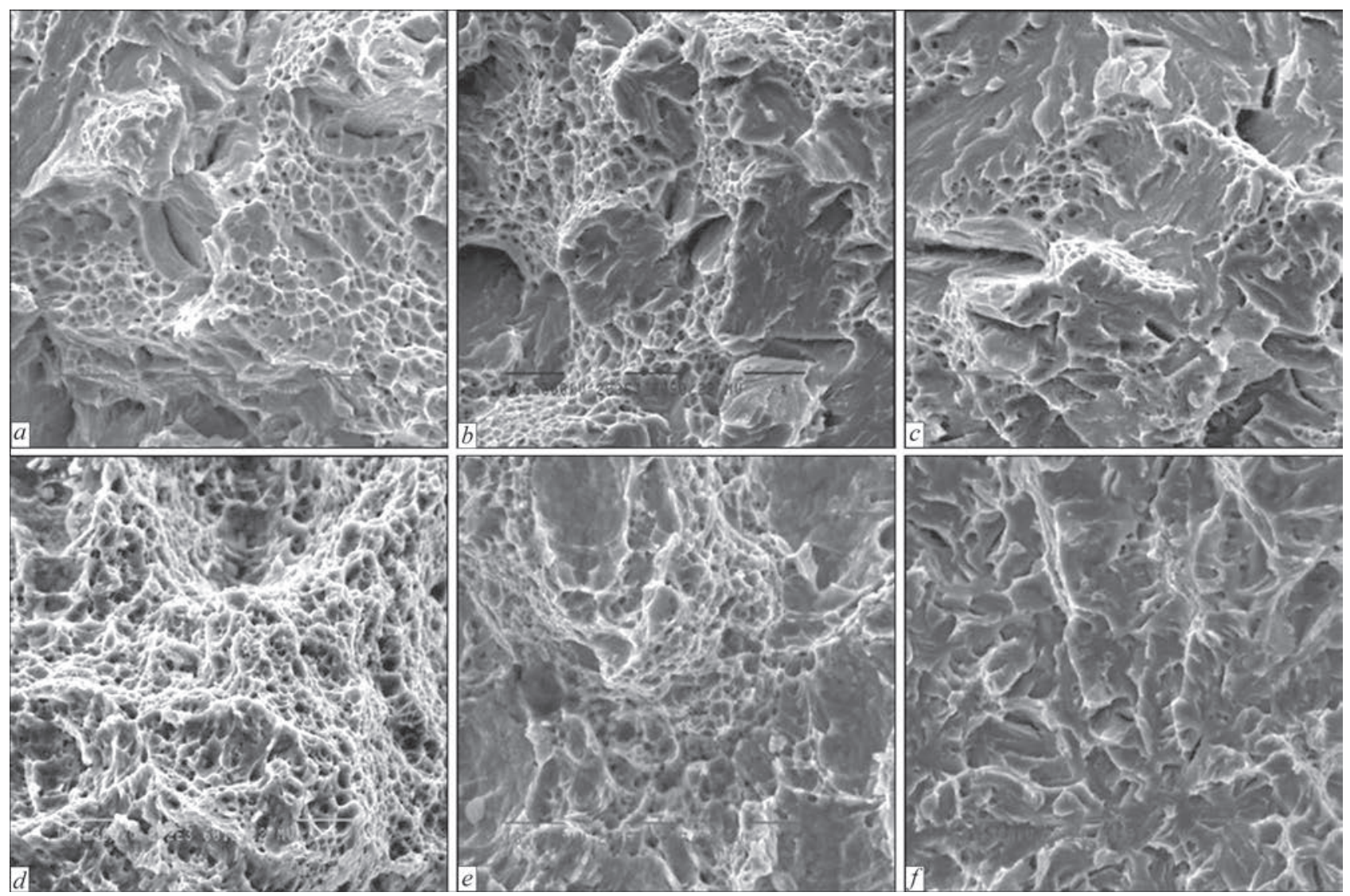

Figure 4. Microstructure $(\times 2020)$ of fracture surface of weld metal $(a-c)$ and HAZ $(d-f)$ of HLA-welded joints in zone of main crack at $T_{\text {test }}=-40^{\circ} \mathrm{C}: a, d-v_{\mathrm{w}}=72 ; b, e-90 ; c, f-110 \mathrm{~m} / \mathrm{h}$

the mechanical properties along the welding zone and reduction of welded joint crack resistance.

Dynamic loading. The investigations of structural changes and their effect on dynamic strength of the welded joint metal depending on welding speed showed the following (Table 2; Figure 4). The results of fractographic SEM examinations of the fractures allowed making a comparison of facture mode of welded joint depending on test temperature in different fracture zones. Thus, ductile fracture type is mainly typical for weld metal at all speeds of welding and $T_{\text {test }}=+20^{\circ} \mathrm{C}$. However, amount (up to $\sim 2 \%$ ) of areas of brittle intracrystalline chip in zone $\mathrm{I}$ is somewhat increases at $v_{\mathrm{w}}=90 \mathrm{~m} / \mathrm{h}$. In the case of $v_{\mathrm{w}}=110 \mathrm{~m} / \mathrm{h}$ the portion of brittle fracture increases to $~ 30 \%$.

The joint metal at $v_{\mathrm{w}}=72$ and $90 \mathrm{~m} / \mathrm{h}$ and $T_{\text {test }}=$ $=-40{ }^{\circ} \mathrm{C}$ is characterized by a mixed type of fracture, i.e. brittle in combination with ductile pit relief in zone I to $\sim 40-55 \%$; in zone II to $70-80 \%$ of brittle chip (Figure $4, a, b)$. Increase (1.3 times) of volume fraction of brittle fracture to 75-95\% (Figure 4, c), coarsening of chip facets and increase of forming cracks extension are observed at $v_{\mathrm{w}}=110 \mathrm{~m} / \mathrm{h}$.

Ductile mode fracture with pit size of $1-10 \mu \mathrm{m}$ (see Table 2) is observed in the nucleus zone I of HAZ at $T_{\text {test }}=-40^{\circ} \mathrm{C}$ for all speeds of welding. In the zone of main crack propagation II at $v_{\mathrm{w}}=72 \mathrm{~m} / \mathrm{h}$ the frac- ture has mainly ductile mode (Figure $4, d$ ) with single areas $(V \sim 5 \%)$ of quasi-brittle constituent. $v_{\mathrm{w}}=$ $=90 \mathrm{~m} / \mathrm{h}$ promotes for the increase of volume fraction of quasi-brittle chip to $V \sim 20 \%$ (Figure $4, e$ ) and that at $v_{\mathrm{w}}=110 \mathrm{~m} / \mathrm{h}$ makes $V \sim 35 \%$ (Figure $4, f$ ). At that, the facets' size is also enlarged in 1.3 times.

Thus, the structure forming at $v_{\mathrm{w}}=72 \mathrm{~m} / \mathrm{h}$ is the optimum metal structure of welds and HAZ in the dynamic strength tests from point of view of fracture mode at different test temperatures.

Cyclic loading. The HLA-welded joints, made at $v_{w}=72 \mathrm{~m} / \mathrm{h}$, were used for investigation of effect of external loading. They were subjected to cyclic bend loading at cycle stress $\sigma_{-1}=60 \mathrm{MPa}$ up to development in it of $2 \mathrm{~mm}$ length fatigue crack from notch apex at $N=800,000$ cycles of loading.

Figure 5, $a$ shows the general view of the fracture surface of sample being examined. The following zones can be outlined on fracture macrostructure, i.e. I - zone of slow propagation of crack in the direction from external (side) surface of the fracture; and II zone of accelerated (main) crack propagation.

Zone I has smoothed surface that indicate the first stage, i.e. fracture nucleation (slow crack propagation). The dimensions of zone I were around $180-230 \mu \mathrm{m}$. This stage is characterized by crack nucleation and their propagation over slip planes. Pres- 


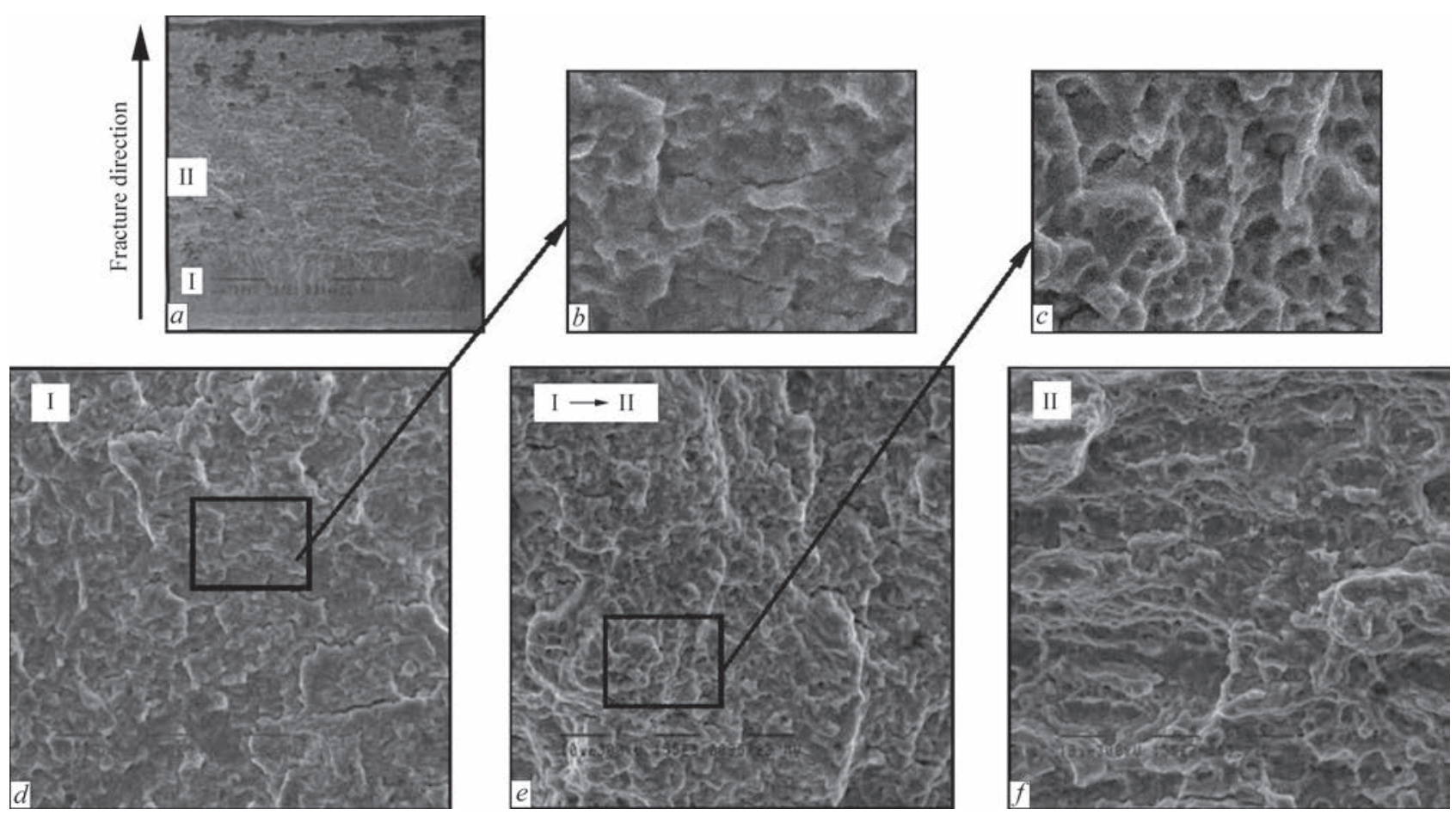

Figure 5. Fracture surface of HLA-welded joint $\left(\nu_{\mathrm{w}}=72 \mathrm{~m} / \mathrm{h}\right)$ after cyclic bend loading $\left(\sigma_{-1}=60 \mathrm{MPa}, N=800,000\right.$ cycles $): a-$ zone of fracture nucleus; $b$ - area of transfer of fracture nucleus to main crack; $c$ - main fracture $(\times 1550) ; d, e$ - corresponding fragments of fracture surface $(\times 4$ magnification)

ence of zone I indicates some duration of the stage of fracture nucleation and, respectively, duration of the process of fatigue crack propagation at nucleation stage, i.e. the welded joint under given conditions of external loading has a crack propagation resistance. The mode of fracture in zone I is quasi-brittle with the local areas of ductile fracture (Figure $5, b, d$ ). A transfer to the main fracture zone from zone I to zone II is characterized by a shift of fracture mode, namely to ductile pit type (Figure 5, c,e,f).

Thus, the structural changes from point of view of mode of HLA-welded joint fracture under conditions of external cyclic bend loading $\left(\sigma_{-1}=60 \mathrm{MPa}\right)$, apparently, should provide for the best properties of strength and crack resistance of metal under service conditions in the case of $v_{w}=72 \mathrm{~m} / \mathrm{h}$.

Examination of fine structure. The detailed TEM examinations were also carried out. They provide for the possibility to study the peculiarities of fine structure of welded metal and its parameters, i.e. change of density and mode of dislocation distribution in different structural constituents (in internal volumes and along the structural boundaries), nature of forming substructure, effective distance between carbide phases and their size. In this connection the following is determined for the welded joints produced at $v_{\mathrm{w}}=72 \mathrm{~m} / \mathrm{h}$ (optimum structure) and $v_{\mathrm{w}}=110 \mathrm{~m} / \mathrm{h}$ (gradient structure).

Formation of the internal substructure with uniform distribution of volume density of dislocations to $\rho \sim(4-6) \cdot 10^{10} \mathrm{~cm}^{-2}$ (Figure 6,a) is observed in the weld metal at $v_{\mathrm{w}}=72 \mathrm{~m} / \mathrm{h}$ in $\mathrm{B}_{\mathrm{L}}$ grains, and dislocation density makes $\rho \sim 8 \cdot\left(10^{10}-10^{11}\right) \mathrm{cm}^{-2}$ in $\mathrm{M}_{\text {temp }}$ structures. $B_{L}$ grain fragmentation is typical for HAZ metal, i.e. $10-20 \%$ refinement of lath $B_{L}$ structure is observed that is accompanied by certain increase of dislocation density (Figure 6,b).

The following is typical for the fine structure of welded joint in the case of $v_{w}=110 \mathrm{~m} / \mathrm{h}$, i.e. integral value of dislocation density in weld metal and $\mathrm{HAZ}$ rises, mainly $\mathrm{B}_{\mathrm{U}}$ structure is formed at the maximum increase of dislocation density to $\rho \sim$ $\sim 1.5 \cdot 10^{11} \mathrm{~cm}^{-2}$ (Figure 6, $c, d$ ).

Thus, it is shown that the most uniform distribution of dislocation density at formation of $\mathrm{B}_{\mathrm{L}}$ structure is provided in HLA welding with $v_{w}=72 \mathrm{~m} / \mathrm{h}$.

Analytical estimations of mechanical and strength properties. The experimental data allowed carrying out an analytical estimation of differential contribution of all structures and their parameters, namely size of grain $D_{\mathrm{g}}$, subgrains $d_{\mathrm{s}}$, dislocation density $\rho$, inter-carbide distances, volume fraction of structures forming along the welding zone in weld metal and in overheating areas, in change of the integral value of yield limit $\sum \sigma_{y}$ of the welded joints depending on welding mode [3-5]. At that, the integral $\sum \sigma_{y}$ value (according to equation including known dependencies of HallPetch, Orowan et al. [6-8]) is the sum value consisting of series of constituents: 


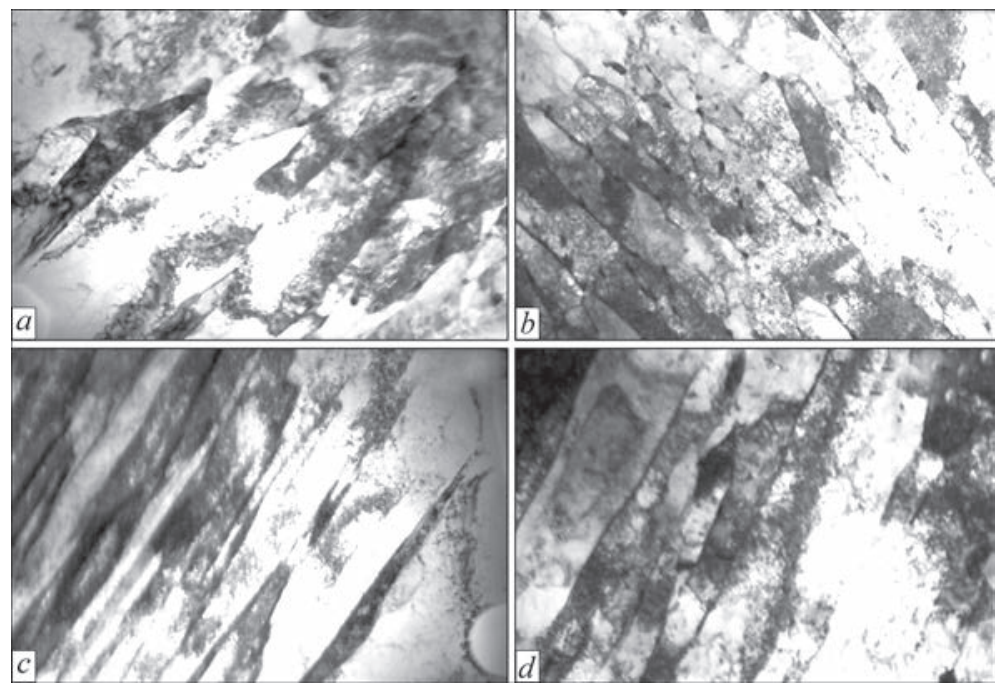

Figure 6. Fine structure of weld metal $(a, c)$ and $\operatorname{HAZ}(b, d): a, b-\mathrm{B}_{\mathrm{L}}$ at $\mathrm{v}_{\mathrm{w}}=72 \mathrm{~m} / \mathrm{h}(a-\times 30000 ; b-\times 20000) ; c, d-\mathrm{B}_{\mathrm{U}}$ at $v_{\mathrm{w}}=$ $=110 \mathrm{~m} / \mathrm{h}(c, d-\times 30000)$

$$
\Sigma \sigma_{\mathrm{y}}=\Delta \sigma_{0}+\Delta \sigma_{\text {s.s. }}+\Delta \sigma_{\mathrm{g}}+\Delta \sigma_{\mathrm{s}}+\Delta \sigma_{\mathrm{d}}+\Delta \sigma_{\mathrm{d} . \mathrm{h}}
$$

where $\Delta \sigma_{0}$ is the resistance of type of metal lattice to free dislocation movement (lattice friction stress or Peierls-Nabarro stress); $\Delta \sigma_{\text {s.s }}$ are the hardening of solid solution by alloying elements (according to the Mott-Nabarro theory); $\Delta \sigma_{\mathrm{g}}$ and $\Delta \sigma_{\mathrm{s}}$ is the hardening due to change of size of grains and subgrains (in accordance with Hall-Petch dependence); $\Delta \sigma_{d}$ is the dislocation hardening caused by inter-dislocation interaction (based on the Taylor-Seger-Mott-Hirsch theory); $\Delta \sigma_{\text {d.h }}$ is the dislocation hardening (due to disperse phases by Orowan) [10-14].

The following is determined as a result of estimations of the changes in welded joint zones of such a strength characteristic as $\sigma_{y}$. The calculation value of yield limit in the weld metal and HAZ at $v_{w}=$ $=72 \mathrm{~m} / \mathrm{h}$ makes $\sum \sigma_{\mathrm{y}} \sim 917$ and $1077 \mathrm{MPa}$, respectively, and the maximum contribution in the yield limit is introduced by substructure $\left(\Delta \sigma_{\mathrm{s}} \sim 318-356 \mathrm{MPa}\right)$, dispersion $\left(\Delta \sigma_{\mathrm{d}} \sim 253-295 \mathrm{MPa}\right)$ and dislocation hardening $\left(\Delta \sigma_{\text {d.h }} \sim 157-180 \mathrm{MPa}\right)$ (Figure 7, a). At that, the

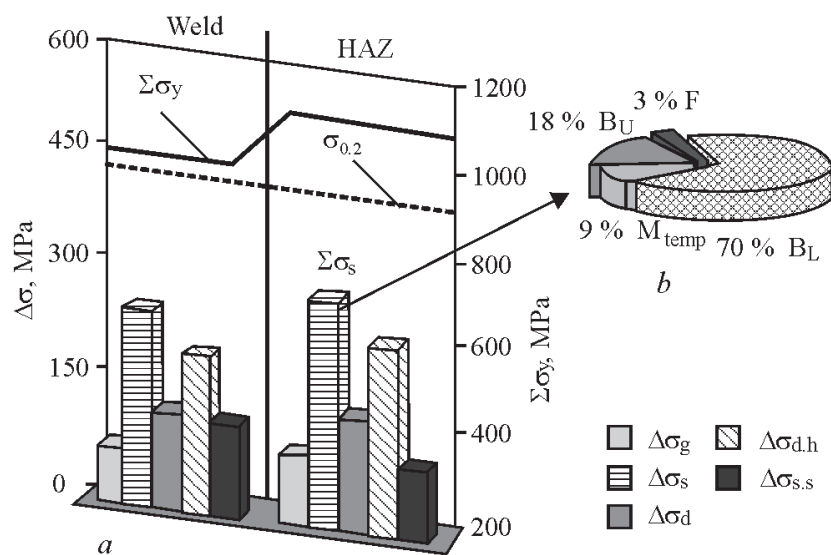

Figure 7. Contribution of different constituents of structural hardening $\Delta \sigma$ in calculation value of yield limit $\Sigma \sigma_{y}$ of weld metal $(a)$, and contribution of structural constituents in change of substructural hardening $\Delta \sigma_{\mathrm{s}}$ at $v_{\mathrm{w}}=72 \mathrm{~m} / \mathrm{h}(b)$ contribution of such a type of structural constituent as $\mathrm{B}_{\mathrm{L}}$ is the maximum one (Figure $7, b$ ).

In the case of $v_{w}=110 \mathrm{~m} / \mathrm{h}$ the total value of yield limit rises (in comparison with $v_{w}=72 \mathrm{~m} / \mathrm{h}$ ) per 10 $15 \%$ (Figure 8 ), that is caused by certain grain structure refining (see Figure $3, c$ ) and 1.3 times increase of the integral value of dislocation density.

Fracture toughness. The calculation values of fracture toughness index, estimated on dependence $K_{1 c}=\left(2 E \sigma_{0.2} \delta_{c r}\right)^{1 / 2}[15]$ (where $E$ is the Young's modulus; $\sigma_{0.2}$ is the calculation value of strengthening; $\delta_{\mathrm{cr}}$ is the value of crack critical opening) according to the data of substructure parameters as well as substitution of $K_{1 c}$ and $\sigma_{\mathrm{y}}$ showed the following (Figures 8 and 9).

In as-welded state at $v_{\mathrm{w}}=72 \mathrm{~m} / \mathrm{h} K_{1 c} \sim 14$ $37 \mathrm{MPa}^{-1 / 2}$ (Figure 9, $a, c$ ). It is kept on the level of $K_{1 c} \sim 20-33 \mathrm{MPa} \cdot \mathrm{m}^{1 / 2}$ (Figure 9, $b, c$ ) as a result of application of external cyclic bend loading $\left(\sigma_{-1}=\right.$ $=60 \mathrm{MPa}, N=800000$ ). This indicates the same crack resistance even under cyclic loading of this welded joint due to formation of B-M structure (mainly $\mathrm{B}_{\mathrm{L}}$ ).

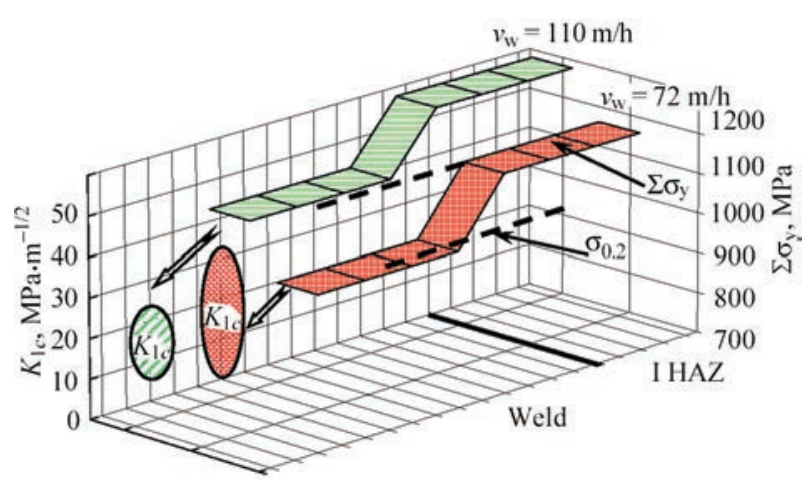

Figure 8. Change of average calculation value of yield limit $\sum \sigma_{y}$ and fracture toughness $K_{1 c}$ for zones of weld and I HAZ HLA welding at $v_{\mathrm{w}}=72$ and $110 \mathrm{~m} / \mathrm{h}$ 


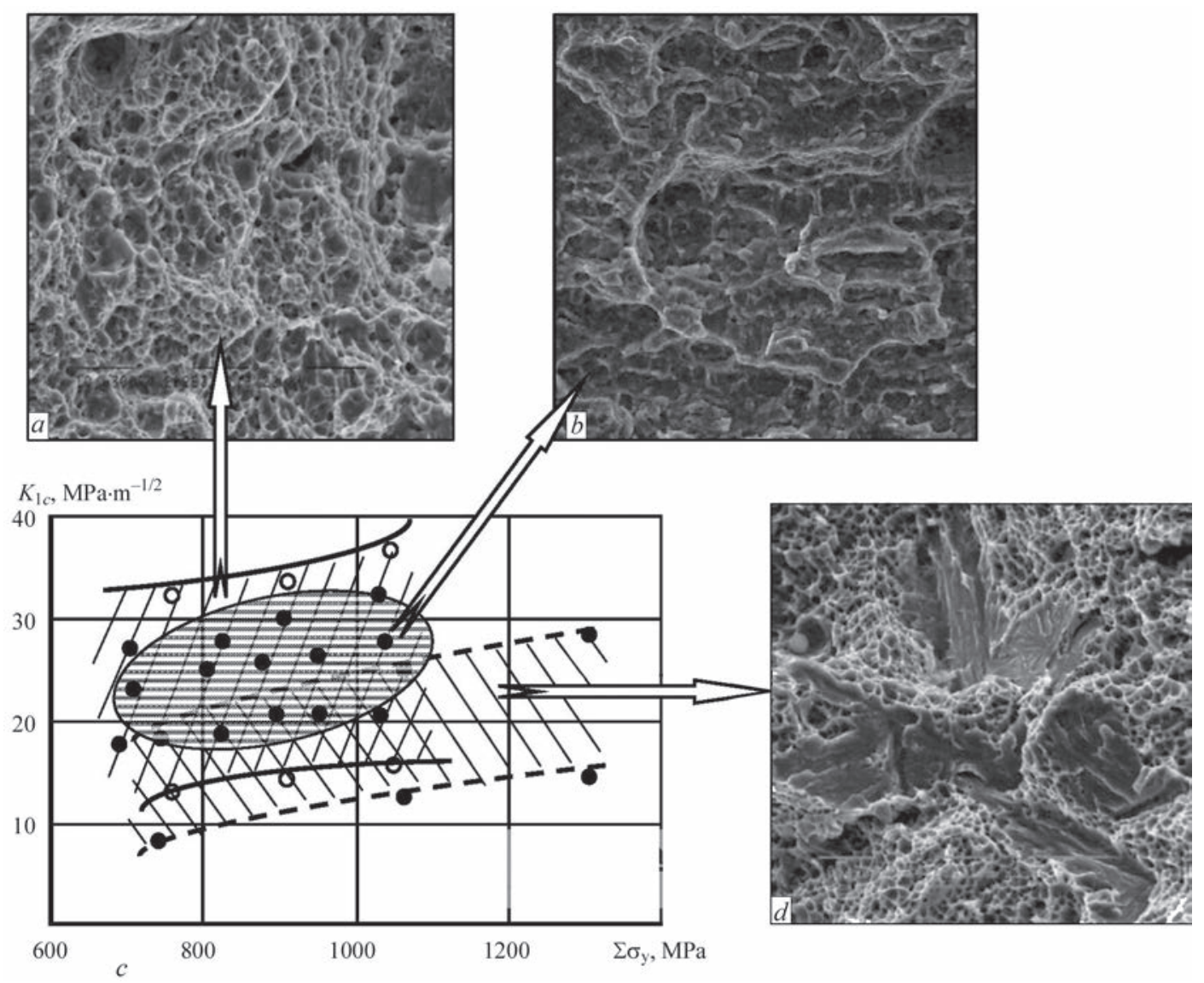

Figure 9. Change of calculation values of strength $\sum \sigma_{\mathrm{y}}$ and fracture toughness $K_{1 c}$ of weld metal (c), patterns of $100 \%$ ductile fracture after welding at $v_{\mathrm{w}}=72 \mathrm{~m} / \mathrm{h}(a)$ and cyclic loading $(b)$ and $20-30 \%$ brittle intragranular chip at $v_{\mathrm{w}}=110 \mathrm{~m} / \mathrm{h}(d)(\times 2020)$

At that, the substructure, and mainly $\mathrm{B}_{\mathrm{L}}$, make the largest contribution in metal hardening and increase of fracture toughness (Figure 9). $K_{1 c}$ index (Figure 9, c) in the case of $v_{w}=110 \mathrm{~m} / \mathrm{h}$ is significantly $(30 \%)$ reduced that results in a brittle intragranular fracture (Figure $9, d$ ). The latter is mainly caused by a formation of other type structure, namely $\mathrm{B}_{\mathrm{U}}$, with corresponding non-uniform distribution of dislocation density.

Crack resistance (local internal stresses). Carried examinations of fine structure also allowed performing the estimation of change of local internal stresses $\tau_{\text {l.in }}$, i.e. zones of crack nucleation and propagation. The estimations were carried out using known dependence $\tau_{\text {in }}=G b h \rho /[\pi(1-v)]$ (where $G$ is the shear modulus; $b$ is the Burgers vector; $h$ is the foil thickness; $v$ is the Poisson's ratio; $\rho$ is the dislocation density) $[10,16,17]$.

It was determined that the maximum values of $\tau_{\text {l.in }} \sim 1900-2800 \mathrm{MPa}$ (that makes $(0.2-0.35) \tau_{\text {theor }}$ ), are formed at $v_{\mathrm{w}}=110 \mathrm{~m} / \mathrm{h}$ in the places of elongated dislocation accumulations $\left(\rho=1.5 \cdot 10^{11} \mathrm{~cm}^{-2}\right)$ along the $\mathrm{B}_{\mathrm{U}}$ boundaries. This results in nucleation of microcracks in these zones and reduction of crack resistance of the welded joints (Figure 10, $a$, $b)$. The lowest values $\tau_{1 . \text { in }} \sim 1500-1900 \mathrm{MPa}$ are typical for the welded joints produced at $v_{w}=72 \mathrm{~m} / \mathrm{h}$, which is promoted by formation of fine-grain and fragmented $B_{L}$ structures in the welding zone in combination with uniform distribution of the dislocations (Figure 10,c,d).

As a consequence it is determined that the optimum strength, ductility and crack resistance of the HLA-welded joints of high-strength steel are provided at $v_{w}=72 \mathrm{~m} / \mathrm{h}$, that is caused by formation of the most disperse structures $-\mathrm{B}_{\mathrm{L}}$, fine-grain $\mathrm{M}_{\text {temp }}$ in the absence of elongated dislocation accumulations (concentrators of $\left.\tau_{\text {l.in }}\right)$.

\section{Conclusions}

1. The complex investigations at all structural levels were used for studying the structure-phase state of the main zones of welded joints of high-strength steel 14KhGN2MDAFB produced at different modes of hybrid laser-arc welding. It is shown that increase of welding speed from 72 to $110 \mathrm{~m} / \mathrm{h}$ provokes for changing in relationship of phase constituents (lower bainite, upper bainite and martensite) forming in the welding zones, i.e. $\mathrm{B}_{\mathrm{L}}$ volume fraction is reduced to 10-20\%, at prevailing $\mathrm{B}_{\mathrm{U}}$ volume fraction (60-70\%) 

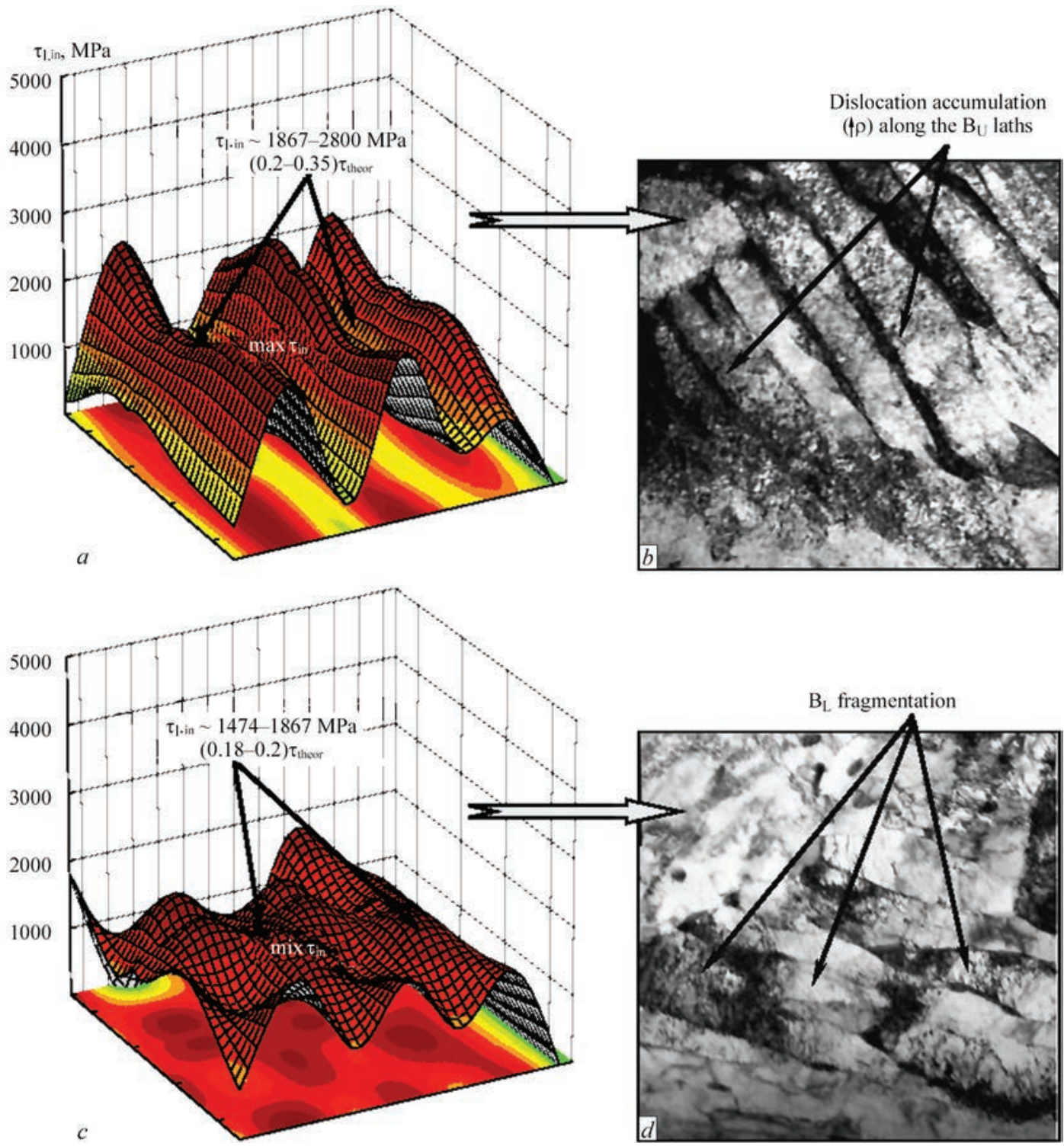

Figure 10. Distribution of local internal stresses $\tau_{\text {l.in }}$ in weld metal of structural zones of $\mathrm{B}_{\mathrm{U}}$ at $v_{\mathrm{w}}=110 \mathrm{~m} / \mathrm{h}(a, b-\times 20000)$ and $\mathrm{B}_{\mathrm{L}}$ at $v_{\mathrm{w}}=72 \mathrm{~m} / \mathrm{h}(c, d-\times 30000)$

and $\mathrm{M}(10-30 \%)$. Presence of the gradients of structural constituents dimensions, microhardness as well as dislocation density is typical at $\nu_{\mathrm{w}}=110 \mathrm{~m} / \mathrm{h}$.

2. Combination of examination at different structural levels with analytical estimations of the mechanical properties of welded joints along the welding zone allowed showing that the constituents of lower bainite and formation of substructure at $v_{\mathrm{w}}=72 \mathrm{~m} / \mathrm{h}$ make the largest contribution in metal hardening $\sum \sigma_{\mathrm{y}}$ and increase of fracture toughness $K_{1 c}$. At that, increase of the crack resistance of welded joint under conditions of external dynamic $\left(T_{\text {test }}\right.$ from +20 to $\left.-40{ }^{\circ} \mathrm{C}\right)$ and cyclic loading $\left(\sigma_{-1}=60 \mathrm{MPa}, N=800,000\right.$ cycles $)$ is provided. Rise of welding speed to $v_{w}=110 \mathrm{~m} / \mathrm{h}$ causes $30 \%$ reduction of $K_{1 c}$ index at some increase of metal hardness (10-15\%) due to preferable formation of upper bainite structures.
3. The estimations of level of local internal stresses taking into account distribution of dislocation densities in the elongated structural zones of their concentration showed that the maximum $\tau_{\text {l.in }} \sim$ $\sim 1900-2800 \mathrm{MPa}$, corresponding to $(0.2-0.35) \tau_{\text {theor }}$ are formed at $v_{\mathrm{w}}=110 \mathrm{~m} / \mathrm{h}$ along the boundaries of upper bainite lath that results in brittle fracture and reduction of crack resistance of the welded joints.

4. The maximum strength, ductility and crack resistance are provided by formation of the structures of $\mathrm{B}_{\mathrm{L}}$ and $\mathrm{M}_{\text {temp }}$ (fine-grain), and uniform distribution of dislocations in absence of the extended dislocation accumulations, i.e. concentrators of local internal stresses.

1. (1965) High-strength steel: Coll. Ed.by L.K. Gordienko. Mos-
cow: Metallurgiya.

2. Houdremont, E. (1959) Special steels. Moscow: Metallurgizdat. 
3. Paul, K., Ridel, F. (2009) Hybrid laser welding — joining the efforts. Fotonika, 1, 2-5.

4. Kah, P., Salminen, A., Martikainen, J. (2010) Laser-arc hybrid welding processes (Review). The Paton Welding J., 6, 32-40.

5. Shelyagin, V.D., Khaskin, V.Yu. (2002) Tendencies in development of laser-arc welding (Review). Ibid., 6, 25-28.

6. Shorshorov, M.Kh., Belov, V.V. (1972) Phase transformations and properties of steels in welding. Moscow: Nauka.

7. Markashova, L.I., Poznyakov, V.D., Berdnikova, E.N. et al. (2013) Specifics of structure of high-strength steel welded joints formed in laser welding conditions. In: Proc. of $6^{\text {th }}$ Int. Conf. on Laser Technologies in Welding and of Materials Processing (2131 May 2013, Katsiveli, Crimea, Ukraine), 51-55.

8. Poznyakov, V.D., Shelyagin, V.D., Zhdanov, S.L. et al. (2015) Laser-arc welding of high-strength steels with yield strength of more than $700 \mathrm{MPa}$. The Paton Welding J., 10, 19-24.

9. Markashova, L.I., Grigorenko, G.M., Poznyakov, V.D. et al. (2009) Influence of thermal cycles of welding and external loading on structural-phase variations and properties of joints of 17Kh2M steel. Ibid., 7, 18-25.

10. Markashova, L.I., Poznyakov, V.D., Berdnikova, E.N. et al. (2014) Effect of structural factors on mechanical properties and crack resistance of welded joints of metals, alloys and composite materials. Ibid., 6/7, 22-28.

11. Markashova, L.I., Shelyagin, V.D., Kushnaryova, O.S. et al. (2014) Structural-phase state and mechanical properties of $38 \mathrm{KhN} 3 \mathrm{MFA}$ steel surface layers formed under conditions of laser and laser-plasma alloying. In: Proc. of $7^{\text {th }}$ Int. Conf. on Mathematical Modelling and Information Technologies in Welding and Related Processes (15-19 Sept. 2014, Odessa, Ukraine), 43-47.

12. Conrad, H. (1973) Model of strain hardening for explanation of grain size effect on metal flow stress. In: Super-fine grain in metals, 206-217. Moscow: Metallurgiya.

13. Petch, N.J. (1953) The cleavage strength of polycrystals. $J$. Iron and Steel Inst., 174(1), 25-28.

14. Kelly, A., Nickolson, R.B. (1966) Precipitation hardening. Moscow: Metallurgiya.

15. Romaniv, O.N. (1979) Fracture toughness of structural steels. Moscow: Metallurgiya.

16. Stroh, A.N. (1954) The formation of cracks as a result of plastic flow. Proc. of Roy. Soc. A, 223(1154), 404-415.

17. Cottrell, A.H. (1958) Dislocations and plastic flow in crystals. Moscow: Metallurgiya.

Received 05.04.2016 